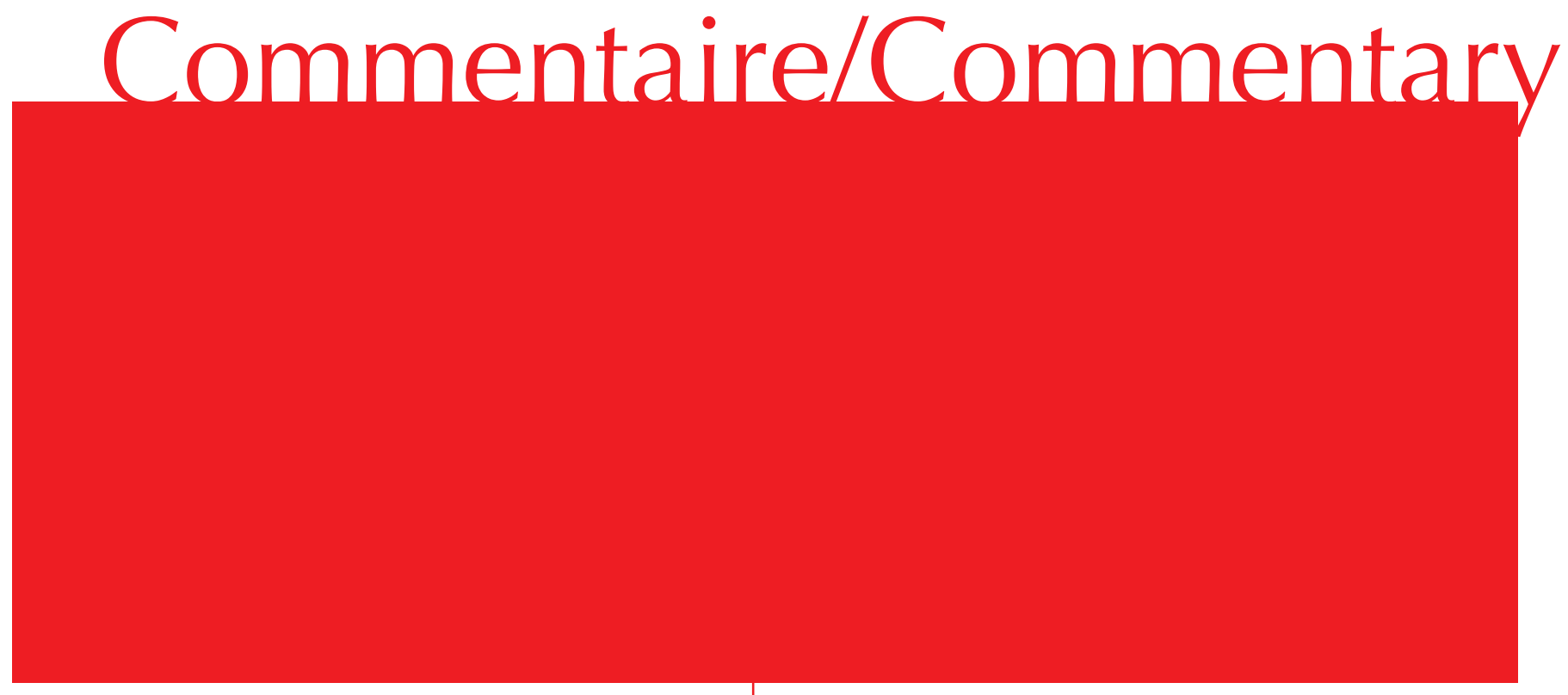

\section{Are there really Two Cultures in the Health Debate? Towards a New Understanding of Autonomy}

\section{IGNAAS DEVISCH}

Exactly fifty years ago, in 1959, Charles Percy Snow held his famous Rede Lecture on the 'two cultures' in science. The Two Cultures and the Scientific Revolution noticed a major gap in scientific thought between scientists and literary intellectuals. Snow considered this caesura as dramatic not only for science but for society as a whole. Since many global problems need incentives from both cultures, their separation hindered the disentanglement of these difficulties.[1] Snow's lecture has been widely discussed ever since, and still today the phrase 'two cultures' is a common understanding. [2]

Although at first glance the current debates on health and healthcare seem to be infected by an analogous gap between two different discourses, we should be selective with quoting Snow's phrase to avoid a further inflation of its meaning. Too often the phrase is used to stipulate different angles or perspectives on a single outcome.[3] While it is true on the one hand that health sciences continue to warn us about unhealthy lifestyles and risk behavior, [4,5] on the other hand, philosophers and sociologists have a full-time job criticizing society for exercising too much control, biopolitics or interference in our private lives. [6,7]

Despite these differences, analyzing current health debates from the perspective of two cultures would be a mistake. This is not because the differences are simply unproblematic or irrelevant, but rather that focusing on them would hinder us from seeing the real deadlock at a more fundamental level, a deadlock we will describe as the 'blinding consensus on autonomy in healthcare today'. This deadlock is not the result of what divides both 'cultures', but of what they share. In short and generally speaking, although their perspectives differ, both 'cultures' obviously presuppose heteronomy as a bad thing that should be avoided. Health scientists and 
policymakers strive for better health, which they perceive as the zenith of individual autonomy: the healthier a person is, the more control he acquires over his or her own life, and thus the more autonomous he or she is. Medical humanities, on the other hand, also have autonomy as their focal point, albeit from a different angle. They propose a type of healthcare that helps the individual decide whether he or she agrees with therapeutic interventions or screenings on risk behavior and predictive parameters.

It is not only these cultures that strive for autonomy in healthcare. Apparently, almost everyone occupied with research on health today is focusing on autonomy. A simple 'all fields' search in the PubMed database produced the following results: 'heteronomy AND health' only gives 4 hits, while 'autonomy AND health' gives us 12,911 hits (search made on 08/21/09). This result is overwhelming. Although most readers will find the remarkable focus on autonomy in health more than appropriate, we will nevertheless question this consensus - not because we adore questioning as such, but because we find interest in heteronomy vital. Although we agree upon autonomy as a desirable objective, heteronomy is not only unavoidable; it is not necessarily undesirable either, unless it is forced upon us by the misuse of power or control.

First of all, at a fundamental (existential) level, heteronomy is unavoidable. Under no circumstances I am always my own (autos) legislator (nomos). From the outset, all of us are exposed to heteronomy and maintain our lives by way of heteronymous means, whether through antibiotics for a simple flu, a blood transfusion or a variety of other operations, not to mention our genetic inheritance. In this way, we are all touched by something other than ourselves; we are all marked by heteronomy. In his book Corpus, the French philosopher Jean-Luc Nancy calls this exposure to one another expeausition - playing on the term 'exposition': 'peau', in French, means skin.[8]

This is even more the case for healthcare. The mere fact that someone is appealing for care means principally that he or she is no longer autonomous and is in need of someone or something else, which is an appropriate definition of heteronomy. Instead of neglecting this or understanding it as the sheer negative side of autonomy, we should deal with it in a positive way and develop theoretical and practical frameworks to integrate heteronomy into health theory and policy.

Secondly, at a more applied level, heteronomy as such is not a bad thing unless it is forced upon us by the misuse of power, paternalism or control and can even be considered necessary. Self-determination and autonomy may be the objectives of healthcare, but it is a principal misunderstanding to claim that heteronomy must be avoided at all costs, both from a theoretical perspective and on a practical level. Autonomy is often desirable but not everyone has a maximization of autonomy as his or her objective. Many people, for instance, do not want to participate in medical decision-making, although they are in favor of patient-centered therapy.[9] The constant occupation to make individual precarious choices in health matters can be oppressive or cause existential stress. For instance: do we want the fetus to live or to be aborted? Can I still sustain that terrible pain or do I prefer euthanasia? And so on. A decade ago, the French sociologist Daniel Ehrenberg linked the increase of autonomy to the rise of depression and anxiety disorders in western societies. He entitled the report of his research, "The exhaustion of being yourself." [10]

And finally, be it a less important argument than above, autonomy is sometimes misused to shirk the clinician's responsibility to the patient. A fashionable concept such as 'patient empowerment', for instance, is abused by clinicians to transfer problematic issues for patients to the responsibility of 'autonomous' patients.[11,12] Of course, a plea for heteronomy will not solve this problem, but we have to be aware of it instead of simply worshipping autonomy.

To conclude: autonomy can be a blessing, but it can also be a curse. Autonomy is desirable in some cases; in others certainly not. Suppose my behavior or my illnesses were simply my autonomous problem would that not be most inconvenient for a patient? [13,14] We are constantly exposed to heteronomy, particularly when it comes down to health or the absence of it, as when we are ill or injured. Therefore, there is a striking need for profound reflection upon heteronomy as a self-reliant category in healthcare. Since heteronomy is generally ignored in health theories and practices, or is only theorized as the appendix of autonomy with concepts like 'relational autonomy', [15] we are unable to conceive the richness of its meaning and the possible opportunities this concept offers for better healthcare. Heteronomy is far more than paternalism or control; it can also mean transfer, trust, [16] helplessness, shared responsibility, belief, et cetera. Therefore, we should not simply wipe it out of our horizon, but should take interest in it as in other topics which are relevant to healthcare. My freedom and autonomy do not stop, as the French philosopher Jean-Paul Sartre once said, where the freedom of others begins; [17] quite the opposite, my freedom and autonomy begin where that of others start. 
Heteronomy is a condition of our autonomy, not an obstacle or something opposed to it.

\section{References}

1.Snow CP. The two cultures. Cambridge: Cambridge University Press, 1966.

2.Baker J. Snow's portrait of science in politics. Nature 2009;459(7243):36-9.

3.McArthur JH, Moore FD. The Two Cultures and the Health Care Revolution: Commerce and Professionalism in Medical Care. JAMA 1997;277(12):985-9.

4.Fuemmeler BF, Pendzich MK, Tercyak KP. Weight, Dietary Behavior, and Physical Activity in Childhood and Adolescence: Implications for Adult Cancer Risk. Obesity Facts 2009;2(3):179-86.

5.von Normann K. The impact of lifestyles and food knowledge on the food patterns of German children. International Journal of Consumer Studies 2009;33:382-91.

6.Rabinow P, Rose N. Biopower Today. BioSocieties 2006;1(2):195-217.

7.Briggs CL, Hallin DC. Biocommunicability: the neoliberal subject and its contradictions in news coverages of health issues. Social Text 2007;25(4):43-67.

8.Nancy J-L, Rand R. Corpus: Fordham University Press, 2008.

9.Salmon P, Hall GM. Patient empowerment and control: a psychological discourse in the service of medicine. Social Science \& Medicine 2003;57(10):1969-80.

10.Ehrenberg A. La fatigue d'être-soi. Dépression et société. Paris: Odile Jacob, 1998.

11.Auerbach S. Should patients have control over their own health care?: Empirical evidence and research issues. Annals of Behavioral Medicine 2000;22(3):246-59.

12.Auerbach SM. Do Patients Want Control over their Own Health Care? A Review of Measures, Findings, and Research Issues. Journal of Health Psychology 2001;6(2):191-203.

13.McLaughlin N. Stop blaming the patient. Penalizing workers for personal health decisions is off-the-mark. Modern Healthcare 2008;38(7):25.

14.McLaughlin N. Where the buck stops. Healthcare needs to stop blaming patients and take responsibility for errors. Modern Healthcare 2006;36(48):22.
15. Ho A. Relational autonomy or undue pressure? Family's role in medical decision-making. Scandinavian Journal of Caring Science 2008;22(1):128-35.

16.Lee Y-Y, Lin JL. Trust but Verify: The interactive effects of trust and autonomy preferences on health outcomes. Health Care Analysis 2009;17(3):244-60.

17.Sartre J-P, Macomber C. Existentialism is a humanism. London: Yale University Press, 2007.

Contact Information for Author:

Ignaas Devisch, Ph.D.

Professor in Ethics, Philosophy, and Medical Philosophy

University of Ghent - Artevelde University College

de Pintelaan 185, 9000 Ghent

Belgium

Email: Ignaas.Devisch@UGent.be 